\title{
Un debate más allá de lo educativo. Los límites insuperables de Sarmiento y Alberdi
}

\author{
A debate beyond education. The insurmountable limits of \\ Sarmiento and Alberdi
}

Oscar Daniel Duarte*

Resumen: El debate entablado entre Domingo Faustino Sarmiento y Juan Bautista Alberdi transcurrió desde mediados del siglo XIX hasta luego del fin de la Guerra del Paraguay. Sin embargo se mantiene vigente ya que plantea la necesidad de llevar adelante las tareas democrático burguesas necesarias para la construcción nacional. No ocurrirá eso en Argentina, más allá del debate, la burguesía oligárquica que tomó el poder en el país mantuvo a este en una situación de relativo retraso en función de sostener vínculos con el imperialismo británico.

Palabras clave: Educación; Argentina; Sarmiento; Alberdi; Construcción nacional

\begin{abstract}
The debate took place between Domingo Faustino Sarmiento and Juan Bautista Alberdi elapsed since the mid-nineteenth century until after the end of the War of Paraguay. However it remains in force and a need to carry out the bourgeois democratic tasks necessary for nation building. It will not happen that in Argentina, beyond debate, the oligarchic bourgeoisie took power in the country maintained this in a situation of relative backwardness in terms of sustaining links with British imperialism.
\end{abstract}

Keywords: Education; Argentina; Sarmiento; Alberdi; national construction

\footnotetext{
* Argentino, Doctor en Historia en la Facultad de Filosofía y Letras de la Universidad de Buenos Aires. Docente e investigador en la misma universidad y del CONICET, especializado en historia de la educación, danielduarte979@gmail.com
} 


\section{Introducción}

En un reciente manual sobre historiografía argentina llamado Historia de la historiografía argentina editado en 2009, los historiadores Fernando Devoto y Nora Pagano, realizan un pormenorizado análisis de las corrientes de pensamiento que se afianzaron entre los historiadores y otros hombres y mujeres de las ciencias sociales de nuestro país. El libro se divide en seis capítulos, y en ellos se encargaran de analizar diferentes corrientes historiográficas en su desenvolvimiento temporal. El capitulo uno, "Surgimiento y consolidación de la Historiografía erudita" describe a la primera de estas corrientes historiográficas ubicándolas desde fines del siglo XIX hasta principios del XX. Entre los textos producidos durante el período debemos incluir textos centrales para nuestro análisis entendiendo que el límite entre bibliografía y fuente se vuelve difuso. Así ocurre con los textos escritos por Domingo Faustino Sarmiento (1811-1888) y Juan B. Alberdi (18101884). Estos son solo algunos ejemplos entre muchos otros que participaron con sus trabajos y su intervención política e intelectual en la construcción del Estado nacional. No desconocemos el hecho de que todo análisis del pasado es una consideración de las particularidades políticas presentes. No obstante tendemos a considerar los escritos realizados por los actores del período estudiado como fuentes dispuestas al análisis.

Los principales textos escritos en las últimas décadas del siglo XIX -nuevamente señalo la dualidad entre bibliografía y fuentes- se vinculan a autores ligados al poder del Estado, a la problemática de su construcción y, como un instrumento más en esa construcción, al tema educativo. El debate entablado por largos años entre Sarmiento y Alberdi ocupa un lugar central en nuestro planteo introduciendo la problemática sobre la orientación productiva nacional. Es clarificador encontrar ya en ellos postulados que vinculan la temática escolar al debate sobre el aparato productivo. Recuperamos esta visión ya que muestra a la educación no como un hecho aislado, sino estrechamente relacionada al tipo particular de construcción nacional.

\section{Breve descripción de la obra de Sarmiento y Alberdi}

Inspeccionar la obra completa de Sarmiento nos lleva a comprender como, en la mentalidad de un personaje central en la dirección política que impulsó la construcción del Estado, la educación jugaba un rol definitivo. Un buen resumen de este pensamiento figura en una serie de documentos compilados por Ricardo J. de Titto en 2010 para editorial El Ateneo en el libro El pensamiento de Domingo Faustino Sarmiento. El estudio de los escritos de Sarmiento resulta clave para entender una línea de pensamiento tantas veces considerada contradictoria como tantas veces fue a histórico su análisis. El libro más famoso y base de su ideología, desarrollada posteriormente en otros escritos e incluso en su accionar político, es sin duda Facundo, o civilización y barbarie en las pampas argentinas. Escrito en 1845 desenvuelve, con una prosa inigualable y en forma de anécdotas muchas veces inventadas, 
las características violentas y atrasadas que limitaban el adelanto nacional. Argirópolis publicado en 1850 , es un programa político, pero también un proyecto imaginario. La propuesta allí consta en tomar el ejemplo de la América del Norte y “...trasplantar ese proyecto íntegro al Plata para garantizar nuestra articulación al mundo moderno..." (Padín, 2007: 10). La obra más propiamente "educativa" de Sarmiento sobresale con sus ya celebres textos Educación popular de 1849 y Educación común de 1853, escritos durante el tiempo en el que inició los más duros debates con Juan Bautista Alberdi. Posteriormente Sarmiento alentó la posibilidad de una producción dirigida desde el Estado a la totalidad del cuerpo educativo, docentes, directivos, inspectores, incluso a aquellos familiares que en cada poblado se comprometieran con la tarea educativa. Un ensayo de esta tarea fueron los Anales de la Educación Común. Fue dirigida en un primer momento por su estrecha colaboradora Juana Manso y publicada con interrupciones desde sus inicios el 1 de noviembre de 1858. La producción educacionista de Sarmiento fue sumamente prolífica. De todos modos la publicación que logró consolidarse, marcó la línea oficial sobre la temática, expresó los debates y las problemáticas de la educación, llegó recién en 1881 con la publicación de El Monitor de la Educación Común, revista de la cual sería director por un breve espacio de tiempo producto de sus discrepancias con los integrantes de la elite vinculados a la dirección del Consejo Nacional de Educación.

Juan Bautista Alberdi, hijo del Salón Literario y de la generación del '37' ${ }^{1}$, construyó su línea en claro enfrentamiento al rosismo. Sin duda su obra principal en la historia nacional fue su libro Bases y puntos de partida para la organización política de la República Argentina de 1852. Principio de jurisprudencia a partir del cual se elaborará al año siguiente la Constitución de la Confederación Argentina. Respondió a la crítica sarmientina con sus Cartas Quillotanas de principios de la década de 1850, aunque su diatriba más cínica se vislumbró en textos como El crimen de la guerra de 1870 -en alusión a la guerra del Paraguay-, Peregrinación de Luz de Día de 1871, o en La barbarie histórica de Sarmiento, reeditado bajo ese título por ediciones Pampa y Cielo en 1964.

Tanto en el caso de Sarmiento como el caso de Alberdi, el focus de sus preocupaciones se centraba en el desarrollo nacional, y para el tal planteaban sus propuestas respecto al tipo de gobierno y de producción convenientes para el país. En cuanto al problema educativo, ambos coincidían en la necesidad de educar a la población con una orientación técnica. Planteaba Alberdi en sus Bases, la necesidad de desarrollar hábitos laboriosos y productivos como camino para moralizar a los pobladores del territorio. El debate, de tinte político sobre el problema que aquejaba a aquella elite, recayó en el problema de la dirección social que debía tomar el desarrollo nacional. Como bien sintetizaría Milciades Peña la disyuntiva entre ambos "Con propiedad puede decirse que la República Argentina

\footnotetext{
${ }^{1}$ Así lo calificó Félix Weinberg en su obra "El Salón Literario de 1837” publicado en 1977.
} 
es apenas el plano o planta de una nación' (Alberdi, Obras Completas, vol. IV, Pág. 149) Sobre este plano, Sarmiento y Alberdi querían inscribir una nación; la oligarquía apenas pudo dibujar una semicolonia." (Peña, 2012: 417).

La producción escrita de Sarmiento continuará ya entrando en la década de 1880 en forma casi obsesiva en torno a una preocupación, el devenir educativo de la Nación. Sin embargo la educación comenzaba a reorientarse, del mismo modo que se acomodaba la dirección política del país. Devoto y Pagano dirán respecto al período abierto en 1880 y caracterizado por la "Historiografía erudita" que

Eran los tiempos en que la educación demandaba dosis considerables de educación patriótica y por ello el pasado adquiría una funcionalidad distinta de la que fuera atribuida a lo largo de las tres décadas posteriores a Caseros. Es en este nuevo contexto en el que se populariza la versión mitrista del pasado argentino, pasado que se convertía ahora en un formidable dispositivo nacionalizador. (Devoto y Pagano, 2009: 69)

\section{Un debate más allá de lo educativo}

La descripción del camino trazado tanto por Domingo Faustino Sarmiento como por Juan Bautista Alberdi no es más que una ilustración biográfica de dos personajes centrales que nos permiten comprender cierto planeamiento de la propuesta sobre la educación Argentina. Sin embargo, la profundidad de las discusiones, la injerencia de ambos en la política nacional y sus planteos, superan por mucho la problemática escolar y nos obligan a estudiar los debates entablados por ellos. Una preocupación atraviesa a la generación de pensadores de la cual Sarmiento y Alberdi formaron parte, la conformación de la "República posible", (Halperín Donghi, 1982). No era un destino manifiesto. La idea en ambos se encontraba fuertemente arraigada a la comprensión de las condiciones materiales existentes, así como a las posibilidades de desarrollo con las que contaba el territorio nacional.

Hijos de la Revolución de Mayo y nacidos en el interior del país, ambos encontrarán en la educación el canal de desarrollo individual que los catapultaría luego a una fecunda y activa vida política. Alberdi, el tucumano, obtiene una beca que le permite estudiar en el actual Colegio Nacional de Buenos Aires y codearse con una generación de jóvenes románticos con quienes conformará luego un círculo político que enfrentará las directivas del gobernador de Buenos Aires. Alberdi será "el más inquieto de los inquietos" (Weinberg, 1977: 49) de los integrantes del Salón Literario. Producto de su prédica incisiva y sus

\footnotetext{
${ }^{2}$ La cita es de Tulio Halperín Donghi en su libro de 1982 "Una nación para el desierto argentino".
} 
demandas sociales conocerá el exilió en 1843, primero por Europa para poco después asentarse en Chile.

Sarmiento, el sanjuanino, pierde en dos ocasiones la beca de estudios que le hubiera permitido viajar a Buenos Aires y debe continuar su educación en la provincia de la que es oriundo. La invasión de José Aldao a la provincia cierra la 'Escuela de la Patria' donde estudiaba Sarmiento, quien debió exiliarse a la provincia de San Luis junto a José de Oro y Albarracín. Al poco tiempo regresó a su provincia, pero los enfrentamientos políticos con las montoneras federales lo llevaron a un nuevo exilio, esta vez en Chile. A partir de allí comenzará un largo proceso de exilios, participaciones militares y viajes de estudio por Europa y los Estados Unidos.

La situación política particular de las provincias sud americanas provocaba en toda una generación la pregunta sobre las condiciones políticas necesarias para encauzar al país en el camino del desarrollo que se avizoraba en Europa y Estados Unidos. El planteo parecía claro: unidad política significaba conformación republicana, la reunión parlamentaria donde entrarían en disputa las diferentes representaciones provinciales de manera equitativa. Una diferencia se planteaba; desde la perspectiva de Sarmiento, la Republica debía conformarse de elementos virtuosos, mientras que la propuesta de Alberdi pareciera ligarse a la conformación de elementos prácticos. ${ }^{3}$ Conformación republicana significaba a su vez centralización y reforzamiento del Estado nacional. Era concebida como la herramienta que permitiría al país entrar en la senda del progreso y el desarrollo -en los términos alberdianos- o sacarlo del barbarismo y la incultura -en términos sarmientinos-. La educación aparecía en ambos discursos como un elemento central.

El vocabulario empleado por Botana en su interpretación del pensamiento político de estos dos autores describe, claro está, tendencias, inflexiones, y no posiciones "absolutas": en el caso de Sarmiento se desprende de sus discusiones fundamentales con Alberdi que valoraba la institución estatal y la noción política de ciudadanía mucho más que su contrincante tucumano. Una república verdadera no podía ser, para Sarmiento, como si pareció serlo por momentos en la escritura de Alberdi, una república de productores enteramente ajenos a los universos de la política activa. (Myers, 2010: 26).

La amistad inicial y sus intereses comunes no los libraran de un largo enfrentamiento político luego de la caída de Rosas. La relación entre Sarmiento y Alberdi será, a partir de entonces, mucho más conflictiva. "Alberdi es nombrado encargado de negocios por la

\footnotetext{
${ }^{3}$ Para profundizar en este concepto ver el libro de Natalio Botana "La tradición republicana" reeditado en 2005.
} 
Confederación en Chile. Sarmiento, sin embargo, está resentido con Urquiza, a quien considera un mero continuador de Rosas, y con Alberdi, a quien Urquiza parece obstinarse en favorecer." (Lojo, 2009: 11).

La conformación nacional los encontrará en posiciones enfrentadas que se dirimirán en infinidad de cartas y publicaciones, así como en la práctica política concreta. Alberdi encontrará en el gobierno de la Confederación su canal de acción más fructífero. Desde las Bases asentará la normativa para la futura Constitución Nacional. Sarmiento llegará él mismo al máximo del poder político, enfrentado a los caudillos y estableciendo un contubernio con las oligarquías provinciales vinculadas al poder porteño. Ninguno de los dos encontrará entre los elementos locales a la clase social progresiva que abriera camino al desarrollo tan esperado.

Luego de la presidencia de Sarmiento - atravesada por la guerra del Paraguay y los inicios del crack económico de 1873-, quedará finalmente demarcada la orientación política y económica determinada para el Estado argentino. Durante las presidencias de Nicolás Avellaneda y Julio A. Roca arribará al poder definitivamente una burguesía intermediaría con fuerte raigambre latifundista- que moldeará a la joven república en pos de sus intereses de clase. No existía entonces, ni siquiera cerca del final del siglo XIX, una clase social revolucionaria que pudiera arrancar la iniciativa de manos de la oligarquía.

\section{Alberdi, Sarmiento y la "evolución social”}

Es usual ver en Domingo Sarmiento la figura clave de la educación pública argentina. Fue entendido así por toda una generación posterior de políticos y educadores normalistas -de fines del siglo XIX y principios del XX-convertidos en herederos del discurso sarmientino sobre el sujeto pedagógico. ${ }^{4}$ Pero no solo los integrantes de la elite retomaron a Sarmiento como el paladín de la educación pública nacional, también educacionistas como Aníbal Ponce, desde la izquierda, resaltaron su obra. De todos modos, la imagen romántica del Sarmiento educador es apenas un aspecto de este personaje sobresaliente en diversos aspectos.

Por otra parte, Alberdi siempre fue vinculado a los aspectos jurídicos que constituyeron las bases legales de nuestra conformación republicana. Su preocupación por la formación de la población no arraigó en la memoria escolar. Podemos encontrar dos motivos principales: Alberdi supo vincularse políticamente a los triunfadores de Caseros, pero mantuvo distancia respecto a los sectores políticos -oligarquías provinciales y dirigentes porteñosque controlaron en última instancia el poder político del Estado. Como segundo motivo

\footnotetext{
${ }^{4}$ Nos basamos para desarrollar esta idea en el trabajo de Adriana Puiggrós Historia de la educación argentina, tomo 1 reeditado en 2006.
} 
entendemos que Alberdi no confiaba per se en el sistema escolar, entendía la necesidad de impulsar una sociedad farmer y trabajadora a partir de la cual se conformara el sujeto social de la nación. Afirmaba que para moralizar al ciudadano, "Se llega a la moral más presto por el camino de los hábitos laboriosos y productivos de esas nociones honestas que no por la instrucción abstracta." (Alberdi, 1974: 77). Despreciaba la ociosidad de las elites intelectuales de las cuales - vale decirlo- el también formaba parte.

El planteo sobre el tipo de educación a impartir no se encuentra distanciado respecto al modelo de país. El debate entre Sarmiento y Alberdi cuenta con un horizonte mucho más lejano que la mera preocupación escolar. En ambos pensadores el planteo central está ligado a la necesidad de desarrollar cierta independencia productiva y un cambio de rumbo respecto al camino ganadero ${ }^{5}$ por el que habían optado los estancieros argentinos. A partir de este planteo se evidencia el vínculo entre la educación formal y el tipo de Estado en la que ésta se proyecta. Un mismo programa educativo en dos Estados de diferente caracterización dará diferentes resultados en tanto que el programa educativo no es más que subyacente a la producción y a las políticas más generales de cada país.

Recuperamos en este punto lo planteado por Adriana Puiggrós cuando afirma que las diferencias entre Alberdi y Sarmiento residen en sus opiniones acerca de los factores determinantes de la evolución social. "La educación jugaba un papel accesorio para Alberdi, porque el comprendía que se requerían sujetos sociales y políticas demandantes de educación, antes que una educación que generara tales sujetos.” (Puiggrós, 2006: 81). En Europa y los Estados Unidos el desarrollo técnico y el desarrollo del mercado interno habían potenciado la demanda social por educación, se imponía con ello un nuevo habitus retomando el término utilizado por Puiggros- producto de la sociedad capitalista. Por otro lado la implantación violenta de esos habitus de manera forzada no podían desarrollar los mismos resultados.

Sarmiento creyó posible que la implantación pedagógica generaría la constitución de nuevos sujetos sociales y de nuevas políticas ${ }^{6}$. Maestros y alumnos vinculados en la

\footnotetext{
5 “La generación, llamémosla sarmientina por darle un nombre abarcador, que postula la modificación de esa estructura ganadera para alcanzar una etapa superior agropecuaria, es la que predica la educación popular, que en aquel momento se define como equivalente a primaria." (Weinberg, 1977: 177).

${ }^{6}$ En su estudio sobre la niñez, Sandra Carli plantea que el interés de Sarmiento en la infancia está directamente relacionado al de la construcción de una sociedad burguesa. En un primer momento como rechazo al orden colonial heredado y al despotismo rosista sufrido en sus primeros años de actividad política. En una segunda instancia, en clara imitación a partir de su experiencia Americana. Tanto Facundo (1845) como Recuerdos de Provincia (1850) son una construcción que ilustra la despreciable infancia premoderna y la anhelada infancia de la modernidad. "La infancia de Sarmiento es caracterizada como la infancia moderna y la de Facundo, como premoderna." (Carli, 2002: 41).
} 
educación básica por una relación de instrucción, construirían un sujeto pedagógico capaz de transformar las costumbres y el estilo de vida de los $\operatorname{argentinos}^{7}$ (Puiggrós, 2006: 82).

\section{Diferentes perspectivas analíticas sobre los planteos de Sarmiento y Alberdi}

Una multiplicidad de autores, de diferentes tradiciones académicas o corrientes políticas, han indagado sobre el pensamiento de Alberdi y Sarmiento. Milcíades Peña, desde una perspectiva materialista ligada al trotskismo, vincula el fracaso de la propuesta de ambos con el definitivo vínculo pro imperialista alcanzado por la dirigencia política argentina a inicios de la década de 1890. El aporte central de su obra fue la de mostrar que la relación entre una burguesía intermediaria, afincada en las riquezas de la producción primaria, y las metrópolis consumidoras de esos bienes no podía permitir un desarrollo independiente a escala nacional.

Peña describe los enfrentamientos entre Sarmiento y Alberdi durante la segunda mitad del siglo XIX. Desde diferentes perspectivas ambos buscaron un mismo objetivo. Alberdi ocupó un lugar relevante luego de la Batalla de Caseros afirmando la base legal de la Confederación. Sarmiento interpretó en Urquiza un nuevo caudillo y prefirió distanciarse; poco a poco se vinculará a cierto sector del autonomismo porteño y de las elites del interior creyendo encontrar en ellos a la clase social progresiva para el desarrollo nacional. Ambos serán traicionados en sus intenciones. ${ }^{8}$

En campos opuestos, Alberdi terminó desvinculado de la oligarquía y sentenciado a la soledad estéril mientras que Sarmiento, vinculado a ella, apoyó crímenes brutales como la guerra del Paraguay. La tradición escolar tuvo por costumbre presentarlos como aliados y realizadores del proyecto nacional. No fue así. Enfrentados a partir de Caseros, ninguno vio realizado su programa; ni la libertad comercial con respecto a Europa propuesta por Alberdi, ni la revolución que convertiría a Argentina en un país autónomo y moderno soñado por Sarmiento.

El reparto de la tierra, el libre acceso al crédito, la educación pública, la democracia, eran tareas esenciales para el desarrollo de una burguesía independiente. A ellas apela

\footnotetext{
${ }^{7}$ Este modelo fue implantado en los Estados Unidos en los casos que se intentó educar a los aborígenes. Bajo el lema Kill the indian, save the man se desarrolló una política inclusiva que probablemente fuera retomada por Sarmiento luego de sus visitas al país del norte. http://historymatters.gmu.edu/d/4929/

${ }^{8}$ Peña elabora aquí una crítica a nuestro entender acertada y muy interesante cuando afirma que este es el peor momento de Sarmiento, es decir, aquel en los que se transforma en aliado de la oligarquía porteña y denigrador de las masas que... "estorbaban la marcha oligárquica hacia la acumulación capitalista y el acuerdo con la Bolsa de Londres." Por otra parte Alberdi apostó a la Confederación y, “...en cuanto a resultados prácticos, erró tanto como Sarmiento... porque ya se ha visto que en las cuestiones esenciales referentes al desarrollo nacional, Buenos Aires y la Confederación coincidían.” (Peña, 2012: 390 y 391 ).
} 
Sarmiento, quien buscó imitar el camino tomado por los Estados Unidos. En este contexto pensó una educación que profundizara un proceso industrializador para liberar finalmente a la Argentina de su base colonial-hispana y permitirle seguir el ejemplar camino del país del Norte. Análogamente, repudiaba la organización económica nacional a partir de la ganadería al punto de vincular el espacio rural a la barbarie frente a la civilización de la urbanidad. Así, la educación daba lugar a una nueva sociabilidad sacando al niño de la naturaleza -el barbarismo- para brindarle una segunda naturaleza -la civilización- por medio de los hábitos logrados con la rutina escolar. "La educación debía dar lugar a una nueva sociabilidad creando en el niño una segunda naturaleza." (Carli, 2012: 50).

Alberdi también fue crítico del parasitismo de la oligarquía Argentina. Pensó en la necesidad de una independencia comercial con respecto a Europa. Afirmaba que la civilización era primordial para un país que buscaba ser independiente. Para poder llegar a contar con libertad política debía tener primero libertad industrial. El programa de Alberdi era, en ese punto, similar al de Sarmiento. El desarrollo nacional debía permitir la independencia industrial y comercial de la Nación. Según Alberdi la instrucción general y gratuita solo podía producir el efecto deseado si venía acompañada del ejercicio práctico de los medios de producción. Así, el conocimiento de tareas tan importantes como comercio, labranza de la tierra y la mejora del ganado, las artes mecánicas y los oficios debían ser el objeto de la enseñanza popular (Alberdi, 1886).

La educación poseía en el pensamiento de Sarmiento un poder transformador que, de no verse acompañado por una estructura acorde, no podría aplicarse a la realidad. Sin embargo el criterio que le asignó a la educación era superador a cualquier propuesta hecha hasta ese momento, y se anteponía a la estructura social. Su fascinación por el sistema escolar Norteamericano lo impulsó a importar tal proyecto pedagógico, pero esta no cuadró con la estructura social que la oligarquía predeterminaba para la Argentina, lo que en varias ocasiones lo llevó a realizar la pregunta “¿Una nación moderna o una nación con olor a bosta de vaca?" tal como lo recuperará Peña, la respuesta la encontró en los hechos demarcados por el sector gobernante.

El optimismo pedagógico de Sarmiento radicaba en el hecho de considerar a la educación en sí misma como un motor transformador. Tal como plantea Renata Giovine "En este proyecto sociocultural, coloca a la educación popular como el principio promotor del cambio social, político y económico." (2008: 54). Para Alberdi la educación sería su resultado final, por eso comprendió la problemática; tanto en Estados Unidos como Europa la educación fue un factor accesorio al desarrollo capitalista. Sarmiento por su parte encontraba en las hordas bárbaras a sujetos necesitados de educación como condición necesaria para el desarrollo nacional. Sarmiento fue partidario de impulsar una política de "arraigo costumbrista", es decir, a la suposición de considerar que por medio de la imitación de características particulares de los países desarrollados se llegaría a un 
desarrollo similar. Así fue que intentó imitar el paisajismo parisino con la importación de gorriones y de ciertos trazados para parques y calles; intentó imitar el "mapa" estadounidense con su Argirópolis; y finalmente, en otro nivel, planteó la necesidad de "importar" maestras norteamericanas para implantar en el país las escuelas norteamericanas que tanto admiraba.

Sin embargo, la pedagogía norteamericana tuvo éxito en el país de los "farmers" y el acelerado desarrollo industrial, y gran capacidad de asimilar a una cultura política democrática a los inmigrantes. En una sociedad como la Argentina, donde el camino elegido por la clase dirigente había sido el establecimiento del Orden sobre un camino del Progreso que no alterara las reglas del latifundio y la dependencia de Inglaterra y pronto de los Estados Unidos, los elementos progresistas y democráticos del pragmatismo transmitidos por las educadoras norteamericanas, serían aplastados por una pedagogía normalizadora. (Puiggrós, 2006: 84).

Peña defiende la figura de Sarmiento y Alberdi exaltándolas al punto de convertirlas en "... los más lucidos y consecuentes teóricos de la necesidad de transformar el país respecto a lo que era en 1853." (Peña, 2012: 380). La animadversión con la que se trataron luego de Caseros está vinculada a la fracción de clase con la que cada uno decidió aliarse para llevar adelante sus postulados. El rechazo de Sarmiento a Urquiza - a quien veía como uno más de los caudillos federales- lo llevó a un duro cruce con Alberdi. "Después de Caseros, militan en campos opuestos: Sarmiento en un frente único con la oligarquía porteña, Alberdi en el bando de la Confederación.” (Peña, 2012: 380). Luego Alberdi denunció la Guerra del Paraguay, Sarmiento la apoyó, ese posicionamiento distanció al primero de los sectores de poder y, nuevamente en el sentido contrario, lo encumbró a Sarmiento hasta la dirección del poder mismo.

No obstante en ese desarrollo, Peña adivina un distanciamiento en la perspectiva de Sarmiento que, en caso de ser cierta, resulta al menos muy tardía. El sanjuanino comprendía los límites que implicaba una propuesta de desarrollo de tipo ganadero. Durante su presidencia intentará forzar una transformación impulsando un tipo particular de educación que no encontrará asidero en el armado productivo nacional. La crisis económica de 1873 pondrá límites a los gastos destinados al área educativa, dando definitivamente por tierra con la propuesta. Sarmiento no romperá con la oligarquía terrateniente luego de ese fracaso. Su interpretación del fracaso del proyecto, de hecho, no acusa directamente a la dirección política. En los hechos Sarmiento acusará a la herencia colonial, a la pobre intervención de las masas o al desarraigo cultural. Él mismo impulsará el recorte en el programa de bibliotecas populares en 1876 e incluso negará la necesidad de la fundación de 
escuelas de Artes y Oficios en uno de los debates entablados con el ministro Pizarro. ${ }^{9}$ Recién en febrero de 1886, en ocasión de su cumpleaños número setenta y cinco, Sarmiento se atreve a denunciar que ninguna de sus previsiones se había cumplido y, frente a los vecinos que fueron hasta su casa a saludarlo afirmaba.

Podéis creerme si os digo que este es el peor pedazo de vida que he atravesado en tan largos tiempos y lugares tan varios, más triste con la degeneración de las ideas de libertad y patria en que nos criamos entonces. (El Censor, 1886).

Poco antes de morir Sarmiento pasaba sus peores momentos, y, contrariamente a lo esperable, dos años después de emitida la Ley 1420, la degeneración de las ideas de libertad era más profunda.

Desde un posicionamiento metodológico que basa su análisis en el estudio de las ideas políticas Natalio Botana plasma la trayectoria de Sarmiento y Alberdi estudiando el origen de su implantación ideológica. Así encuentra en Alberdi un afincamiento en el pensamiento ilustrado; "Mientras Sarmiento arrancó de Rousseau y Franklin el paradigma de la ciudad virtuosa y lo trasplantó a la ciudad de la independencia, Alberdi se apropió de la lógica del discurso político que contenían esos textos." (Botana, 2005: 284) Busca el camino que realizaron ambos para alcanzar su concepción republicana a través de la virtud de los individuos, la pureza de los modelos y la imitación -o no- del orden europeo, en la búsqueda del proyecto nacional.

Pero los posicionamientos tomados por cada uno no se deben simplemente a una cuestión de "lecturas", sino a una concepción distinta respecto al modelo de Estado-Nación a partir del desarrollo de experiencias propias, sumado a una mirada homogeneizante respecto del sistema educativo de los Estados Unidos. La concepción de la educación como rasero civilizatorio es propia de las políticas educativas implantadas para "domesticar" a los pueblos originarios mientras que la educación práctica está estrechamente ligada a la ética protestante. $^{10}$

La principal preocupación alberdiana es la pregunta por la constitución del poder, cuya centralización se lograría mediante la construcción de una "republica de habitantes", que según Botana, cobraría el perfil de un régimen sin mediadores políticos. Sarmiento vio en ese desvió -la desvinculación de las masas respecto a la participación política-, la

\footnotetext{
${ }^{9}$ Este concepto fue extraído del texto de Verónica Oelsner "La búsqueda de modelos educativos en el extranjero y los factores condicionantes de las distintas preferencias: el debate de Pizarro y Sarmiento en Argentina en 1881." Publicado en el Anuario de la SAHE N ${ }^{\circ} 8$ de 2007.

${ }^{10}$ Para desarrollar este concepto puede consultarse el texto de Pablo Pozzi y Fabio Nigra citado en la sección bibliografía.
} 
repetición de los síntomas del atraso. Por lo que buscó reemplazar la "Utopía" de la república democrática por una república aristocrática; la ciudadanía debía ampliarse mediante la educación. Al no conseguirse los objetivos buscados mediante la educación debido a la continuidad del régimen de notables afirmados al control de la republica y a que el cuerpo inmigrante no se nacionalizaba- profundizó el camino. "Como educador, en el crepúsculo, Sarmiento quiso la centralización educativa (...) La centralización educativa se vació entonces en el molde de la centralización estatal cuyo poder crecía a medida que disminuía el de las autonomías provinciales.” (Botana, 2005: 468).

Detrás de estos objetivos, el proyecto educativo que finalmente se impone en la década de 1880 opta por una educación humanístico-enciclopédica, frente a la orientación técnica propuesta. Alberdi plantea que no es necesario este tipo de formación para moralizar al ciudadano. Sarmiento, por su parte, concibió a la educación como el factor prioritario en el proceso de cambio y modernización. Juan Carlos Tedesco (su libro clásico Educación y sociedad fue reeditado en 2009) muestra como la educación en Sarmiento tiene un doble propósito. Por un lado, promover el aumento de la producción a través de la preparación de personal capacitado y de la promoción de la estabilidad política necesaria para que las funciones de producción se realicen normalmente. Por otro, promover el respeto de la vida y la propiedad privada.

También Gregorio Weinberg mostró la significativa importancia de la educación para Sarmiento, tanto como una educación política, económica y social, como herramienta formativa para acercarse al "conocimiento de las 'cartillas' a través de las cuales se difundirían las conquistas, asombrosas para la época, de la Revolución Agrícola e Industrial que conmovía a Estados Unidos y Europa Occidental.” (Weinberg, 1995: 176).

En su libro Una nación para el desierto argentino, Tulio Halperín Donghi analiza la formación de Sarmiento y de Alberdi, pero sobre todo nos muestra la imagen formada por ellos del período posrosista. Desarrolla la preocupación que cada uno tiene sobre el nuevo Estado que debía ocupar el lugar dejado por el vacío tras la caída del ex gobernador de Buenos Aires, y cuál sería la finalidad de la educación en ese Estado aun naciente. Por un lado, la preocupación de Domingo F. Sarmiento fue la de encontrar un orden "Republicano", un proyecto educativo que consolidara la paz social frente a cualquier prédica disolvente. Critica aquí la posibilidad revolucionaria socialista que ve en los procesos europeos de 1848, pero también se compromete con el laicismo al enfrentar el proyecto reaccionario de Félix Frías quien, para 1837, proponía un orden con el dominio de "los mejores", donde las masas se comprometieran con un código moral y de creencias ligados al catolicismo. Por otra parte Halperín Donghi tilda de "autoritarismo progresista" el proyecto de Juan Bautista Alberdi. Éste, frente al ejemplo de las revoluciones europeas, planteará que la forma en que la elite debía mantener la disciplina era a través del rigor político y del activismo económico que considera posible dentro del capitalismo. 
Como explicábamos antes, el debate entablado dará como resultado las bases del proyecto educativo para el país naciente. Pero dicho proyecto no será establecido en forma tan directa, sino mediado por los intereses de la clase dominante. La dialéctica del proceso podemos encontrarla en una frase que sintetiza el análisis.

En suma, mientras la Argentina parece haber encontrado finalmente el camino que le había señalado Alberdi, y haberse constituido en una república posible, hay un aspecto de la previsión alberdiana que se cumple mal: el Estado no ha resultado ser el instrumento pasivo de una elite económica cuyos objetivos de largo plazo sin duda comparte, pero con la cual no ha alcanzado ninguna coincidencia puntual de intereses e inspiraciones. (Halperín Donghi, 1982: 146).

Esta breve reseña de diversos autores sobre la perspectiva de Sarmiento y Alberdi nos permite aproximarnos a una problemática del presente. El pensamiento de Domingo Faustino Sarmiento así como el de Juan Bautista Alberdi, fue interpretado casi tantas veces como fue analizado, en muchos casos desvinculado del contexto histórico. El estudio de ambos a partir de la historia de las ideas políticas o incluso de tipos ideales ${ }^{11}$ (Weber, 1998) separa el desarrollo del proceso histórico, lo que lleva a una incomprensión en el planteo final. Sarmiento y Alberdi tenían una preocupación política, sus postulados se establecían en directa correlación con el desarrollo material de la sociedad en la que coexistieron.

\section{Los límites insuperables de Sarmiento y Alberdi}

Tal como fueron planteadas por ellos, las propuestas educativas de Alberdi y la de Sarmiento fueron alternativas respecto a la que finalmente se aplicó desde el Estado. Éste se valió de los lineamientos generales de laicidad y gratuidad pero no desarrolló en forma estructurada la educación de oficios, sino que dio un giro humanístico-enciclopédico con el fin de convertir a la educación en un elemento de moralidad frente a un proyecto de Estado ya planeado y -para 1884 fecha en que se emite la Ley 1420- ya puesto en marcha.

Para Alberdi la educación actuaba en forma secundaria frente a la necesidad de un desarrollo transformador en el aparato productivo nacional. Su propuesta planteaba que, una vez entrando al capitalismo en forma independiente, "la instrucción, para ser fecunda, ha de contraerse a ciencias y artes de aplicación, a cosas prácticas, a lenguas vivas, a conocimientos de utilidad material e inmediata." (Alberdi, 1964: 77). Sarmiento partía de lo contrario, asignando a la educación un poder transformador por delante del desarrollo material y en paralelo a la constitución de la República. Ese poder transformador "libra de la barbarie" tal como lo plantea Sarmiento en su Facundo, y puede influir en el carácter de

\footnotetext{
${ }^{11}$ El concepto es trabajado y analizado por el sociólogo alemán Max Weber el su clásico La ética protestante y el espíritu del capitalismo.
} 
toda una población: "de todas las circunstancias ya naturales, ya artificiales, que influyen en el carácter de las poblaciones, debe concederse la mayor parte a la educación, y la segunda al gobierno o a la religión." (Sarmiento, 1987: 50). Sarmiento, no obstante su laicismo, consideraba a la religión un elemento clave y necesario para el control social. Su oposición era determinada por su liberalismo y la inmediata asociación de la Iglesia Católica con los restos de españolismo. Su vinculo con la Iglesia Católica, por otro lado, fue por momentos de sumisión y de admiración, como ocurrió con respecto al Papa Pio IX tal como puede verse en la carta que Sarmiento envía desde Roma el 6 de abril de 1847 al obispo de Cuyo o bien en el discurso dado en el banquete ofrecido por la sociedad masónica con ocasión de su elección presidencial el 29 de Septiembre de $1868 .{ }^{12}$

Sarmiento nunca asumió una posición de oposición a la Iglesia y fue menos laico que los liberales mexicanos. Era creyente y consideraba que la religión tenía un papel que cumplir en la cohesión de la sociedad. Además su enfrentamiento con el viejo bloque histórico no era profundo. Considerando el eterno peligro de resurrección de la "barbarie", que tan bien expresa Sarmiento en las primeras páginas de Facundo, la Iglesia era un aliado potencialmente necesario.” (Puiggrós, 2006: 91).

Ambos tuvieron una posición ambigua frente a la religión, pero en esa ambigüedad Alberdi demostró más distancia ya que para él, una sociedad fuerte que se sustentara en el desenvolvimiento republicano necesitaba de una distancia con la iglesia.

En nuestros planes de instrucción debemos huir de los sofistas, que hacen demagogos, y del monarquismo, que hace esclavos y caracteres disimulados. Que el clero se eduque a sí mismo, pero no se encargue de formar nuestros abogados y estadistas, nuestros negociantes, marinos y guerreros. ¿Podrá el clero dar a nuestra juventud los instintos mercantiles e industriales que deben distinguir al hombre de Sudamérica? ¿Sacará de sus manos esa fiebre de actividad y de empresa que lo haga ser el yankee hispanoamericano? (Alberdi 1964, 77).

Bien en lo educativo, bien en lo religioso, el enfrentamiento en las posiciones de ambos se vinculaba a los límites que encontraban por intentar imponer sus ideas en un marco social distinto de aquel donde estas pudieran prosperar. El resultado fue un enfrentamiento político y personal, con acusaciones cruzadas frente a sus alianzas políticas. Sarmiento demostró su celo cuando Urquiza optó por la guía política de Alberdi. Luego de un intercambio relativamente cordial Alberdi atacó a Sarmiento con sus Cartas Quillotanas,

\footnotetext{
${ }^{12} \mathrm{El}$ discurso puede leerse completo en la página web http://www.elhistoriador.com.ar/documentos/organizacion_nacional/sarmiento_y_la_masoneria.php
} 
Sarmiento respondió con las Ciento y Una. En clara diatriba contra Sarmiento, Alberdi afirmaba respecto de quien considerar bárbaro;

El obrero productor de esa riqueza, el obrero de los campos, es el gaucho, y ese gaucho a que Sarmiento llama bárbaro, comparable al árabe y al tártaro del Asia arruinada y desierta, representa la civilización europea mejor que Sarmiento, trabajador improductivo, estéril, a título de empleado vitalicio, que vive como un doméstico de los salarios del Estado, su patrón. (Alberdi 1964, 26).

Sarmiento respondió personalmente en una carta de 1853.

En la olla podrida que ha hecho usted de Argirópolis, Facundo, la Campaña, etc., etc., condimentados sus trozos con la vistosa salsa de su dialéctica saturada de arsénico, necesito poner orden para responder y restablecer cada cosa en su lugar. Por ahora me basta fijar las cuestiones primordiales. ¿De qué se trata en sus cartas quillotanas? De demoler mi reputación. ¿Quién lo intenta? Alberdi. ¿Qué causa lo estimula? Ser empleado para ello. ¿Cómo le vino ese empleo? Negociándolo por medio de Gutiérrez ${ }^{13}$, a trueque de escribir en Chile. ¿Cuál es el resultado de su libro? Dejar probado que no soy nada y que usted lo es todo. (AlberdiSarmiento, 2011: 263).

\section{Alberdi rectificó diciendo}

¿Por qué escribo? ¿Para qué he escrito las Cartas, preguntáis? Os lo diré. No para demoler la reputación de Sarmiento, como pretende él con más jactancia qué razón; sino para desarmar a un agitador; para inutilizarle sus armas de desorden, dejándole la gloria que adquirió antes con sus armas de libertad. He escrito mis Cartas por el mismo estímulo que me hizo escribir mis Bases. Ambos escritos son conservadores; el mismo espíritu de orden y disciplina prevalece en los dos. (Alberdi-Sarmiento, 2011: 179).

No solucionaran ese enfrentamiento ni aun cuando el fracaso de sus propuestas los llevó a recluirse poco antes del fin de sus días.

\footnotetext{
${ }^{13}$ Juan María Gutiérrez también fue miembro del Salón Literario y desde allí mantuvo una notable cercanía con Alberdi. Viajaron juntos por América y Europa hasta que se asentaron en Valparaíso en 1843. Luego de la caída de Rosas actuó como miembro del Congreso General Constituyente de 1853 y ministro de relaciones exteriores de la Confederación. (Esta nota no corresponde a la cita).
} 


\section{Conclusión}

Alberdi interpretó que la República Argentina se constituía apenas como el plan de una Nación. Peña hará un análisis profundo de ese concepto "Sobre este plano Sarmiento y Alberdi querían inscribir una nación: la oligarquía apenas pudo dibujar una semicolonia." (Peña, 2012: 417). Hacia fines del siglo XIX no existía en Argentina una clase social progresiva que desarrollara los mecanismos nacionales en forma revolucionaria. La burguesía intermediaría que se constituyó como clase dirigente no podía llevar hasta el final esas tareas debido a sus vínculos diplomáticos y económicos con el imperialismo. Por otro lado tampoco existía aun en la Argentina una clase obrera que pudiera tomar esas tareas en sus manos.

En este artículo hemos puesto de relieve los diferentes posicionamientos de quienes fueron considerados por múltiples autores como los más lucidos exponentes de la política argentina del siglo XIX, mostrando además los limites que debieron enfrentar ambos al no encontrar en la clase política un sector que pudiera impulsar sus propuestas para el área educativa así como productiva.

Asimismo reseñamos en forma breve a una serie de autores muy relevantes para contraponer sus posturas a partir de los cuales intentamos describir los debates planteados previos a la presidencia de Sarmiento.

En los análisis hechos por Sarmiento y Alberdi podemos observar además un punto determinante para la progresión de su devenir político. Ambos pusieron su confianza en diferentes fracciones de las elites latifundistas provinciales distanciándose de la posibilidad de la acción política de las masas. En el fulgor de sus vidas aun no existía en el país un movimiento obrero conformado como si ocurría en Europa y, como ya vimos, lo que podemos llamar "las masas" eran vistas por Sarmiento como sujetos "necesitados" de educación. De todos modos ambos también objetaron los movimientos revolucionarios europeos desde los levantamientos de 1848 hasta la Comuna de Paris de 1871. Es un indicio sobre como entendían la política. Sarmiento describió los sucesos europeos como hechos barbáricos que solo la buena educación -la que educa en la propiedad privada- podía evitar. En su utopía por la construcción de un orden burgués norteamericano Sarmiento quería; "reducir las diferencias sociales sin anularlas." (Carli, 2012: 49). He ahí uno de los límites más importantes en la encrucijada alberdiana y sarmientina, su confianza en una burguesía oligárquica y su desconfianza en una masa social con un destino errante. 
Así, mientras la clase obrera se encontraba aun en ciernes, la burguesía ya había encontrado sus límites en los intereses que los aunaban al Imperio Británico. ${ }^{14}$

El proyecto de Sarmiento, al igual que el de Alberdi, apelaba a una transformación general que superara el problema educativo. Un proyecto de nación independiente al que la oligarquía terrateniente ni siquiera aspiraba, y a la que solo asomó una fracción de ella frente al impacto de las diferentes crisis económicas. He ahí la soledad de Alberdi y los errores de Sarmiento al no encontrar ninguno de los dos una clase social revolucionaria que para esa fecha pudiera concretar sus proyectos, el primero quedó aislado, el segundo vinculado a la clase social que tantas veces había criticado.

Las esperanzas de Sarmiento y de Alberdi estaban puestas en una clase social que no era revolucionaria ni podía serlo. La burguesía argentina no pudo hacer lo mismo que su homóloga norteamericana o europea. No pudo dar salida a los intereses nacionales y la educación pública, como una de sus tareas, encontró pronto los mismos límites que la clase social que la impulsó.

La educación solo podía comportarse como una tarea democrático-burguesa en el marco de un Estado que haya permitido el desarrollo independiente de la Nación. En el ideario de Sarmiento y Alberdi esto era claro. Como hemos señalado a lo largo de este trabajo, ambos ven la necesidad de un proyecto nacional independiente, donde la educación juegue un papel primordial. Pero la nueva etapa abierta con el imperialismo (y el impacto de la crisis de 1873) hará evidente que cualquier desarrollo independiente requerirá de una lucha que la oligarquía terrateniente argentina no estaba dispuesta a dar. Un nuevo período donde la tarea de educación pública solo podía vincularse a los intereses populares y apoyarse en ellos para que se realice como un elemento verdaderamente transformador. La educación pública en abstracto no significa nada, solo vinculada a un proyecto de clase puede convertirse en un verdadero proyecto renovador. La oligarquía terrateniente vio esto con mayor claridad y defendió la educación pública, pero vinculada a su proyecto semicolonial.

Recibido: 23 abril 2015

Aceptado: 21 julio 2015

\footnotetext{
${ }^{14}$ En los Estados Unidos, país que era visto como modelo por ambos, ya se había conformado una importante clase obrera y una burguesía fuerte librada desde hacía años del influjo diplomático inglés. Es importante señalar que el modelo que miran tanto Sarmiento como Alberdi es propio del desarrollo de un Estado imperialista que ya estaba en marcha. Por lo tanto, dicho modelo, solo podía funcionar en el contexto de expansión económica, social y cultural que emerge del colonialismo.
} 


\section{Bibliografía}

Botana, Natalio. La tradición republicana. Alberdi, Sarmiento y las ideas políticas de su tiempo. Buenos Aires: Sudamericana, 2005.

Carli, Sandra. Niñez, pedagogía y política. Transformaciones de los discursos acerca de la infancia en la historia de la educación argentina entre 1880 y 1955. Buenos Aires: Miño y Davila, 2002.

De Titto, Ricardo. El pensamiento de Domingo Faustino Sarmiento. Buenos Aires: El Ateneo, 2010.

Devoto, Fernando y Pagano, Nora. Historia de la historiografía argentina. Sudamericana, Buenos Aires: Sudamericana, 2009.

Giovine, Renata. Cultura política, ciudadanía y gobierno escolar. Tensiones en torno a su definición: la provincia de Buenos Aires (1850-1905). Editorial Stella, Buenos Aires: Editorial Stella, 2008.

Halperín Donghi, Tulio. Una nación para el desierto argentino. Buenos Aires: CEAL, 1982.

Lojo, M. Rosa. "Alberdi el paradójico." En de Titto, Ricardo, El pensamiento de Juan Bautista Alberdi. Buenos Aires: El Ateneo, 2009.

Myers, Jorge. "La contundencia ambivalente: Sarmiento, republicano, liberal y conservador, en la disputa por la construcción de la nación.” En de Titto, Ricardo, El pensamiento de Domingo Faustino Sarmiento. Buenos Aires: El Ateneo, 2010.

Oelsner, Verónica. "La búsqueda de modelos educativos en el extranjero y los factores condicionantes de las distintas preferencias: el debate de Pizarro y Sarmiento en Argentina en 1881.” En Anuario de la SAHE n 8. Buenos Aires: Prometeo, 2007.

Padín, Luis. Domingo Faustino Sarmiento. Argirópolis, los Estados Unidos del Río de la Plata. Buenos Aires: Ed. GEU, 2007.

Peña, Milcíades. "Alberdi, Sarmiento, el 90. Limites del nacionalismo argentino en el siglo XIX.” En Peña, Milcíades Historia del pueblo argentino. Buenos Aires: Emecé, 2012.

Pozzi, Pablo y Nigra, Fabio. La decadencia de los Estados Unidos. De la crisis de 1979 a la Megacrisis del 2009. Buenos Aires: Maipue, 2009. 
Puiggrós, A. -dir.- Historia de la educación Argentina, I. Sujetos, disciplina y currículo en los orígenes del sistema educativo argentino (1885-1916). Buenos Aires: Galerna, 2006.

Weber, Max. La ética protestante y el espíritu del capitalismo. Madrid: Albor, 1998.

Weinberg, Félix. El salón literario de 1837. Buenos Aires: Hachette, 1977.

Weinberg, Gregorio. Modelos educativos en la historia de América Latina. Buenos Aires: AZ editora, 1995.

Fuentes.

Alberdi, Juan y Sarmiento, Domingo. Cartas quillotanas y Las ciento y una. Buenos Aires: emecé, 2011.

Alberdi, Juan. Obras completas. Tomo IV. Buenos Aires: Tribuna Nacional, 1886.

---------- . La barbarie histórica de Sarmiento. Buenos Aires: Pampa y Cielo, 1964.

---------- . Bases y puntos de partida para la organización nacional. Buenos Aires: Plus Ultra, 1974.

El Censor, 16 de febrero de 1886.

Sarmiento, Domingo. Facundo, civilización y barbarie. México D.F.: Porrúa, 1980.

. Educación común. Buenos Aires: Solar, 1987. 